\title{
Left ventricular remodelling and prosthetic valve function after transcatheter aortic valve implantation: A serial cardiac magnetic resonance imaging study
}

\author{
Constanze Merten ${ }^{1 *}$, Hans Beurich ${ }^{1}$, Dirk Zachow ${ }^{2}$, Mohamed El-Mawardy ${ }^{1}$, Gert Richardt ${ }^{1}$, \\ Mohamed Abdel-Wahab'
}

From 18th Annual SCMR Scientific Sessions

Nice, France. 4-7 February 2015

\section{Background}

Transcatheter aortic valve implantation (TAVI) has become a common procedure for high-risk patients with severe aortic stenosis. Aortic regurgitation (AR) is commonly seen after TAVI, but little is known about how it evolves over time. Similarly, the impact of TAVI on left ventricular (LV) function, LV volumes and mass is not well defined.Paravalvular aortic regurgitation (AR) is frequent after TAVI. Yet, little data is available about temporal changes of AR and the impact of TAVI on left ventricular (LV) function and dimensions.

We used cardiac MRI to evaluate LV function, volumes and mass, the occurrence and degree of AR in the early and medium-term follow-up after TAVI.

\section{Methods}

In 81 patients who underwent transfemoral TAVI using the Medtronic Corevalve prothesis or the Edwards Sapien valve we performed baseline cardiac MRI at a median of 11 days after TAVI and follow-up MRI 6 months later.

LV volumes and function were assessed using standard cine MRI sequences. Additionally, phase contrast imaging was conducted to measure aortic regurgitation.

A calculated RF of $1 \%-15 \%$ was graded I (mild), 16\%$30 \%$ was graded II (moderate), 31\%-50\% was graded III (moderate to severe) and $>50 \%$ was graded IV (severe), a $\mathrm{RF}<1 \%$ was classified as no AR.

${ }^{1}$ Cardiology, Herzzentrum Bad Segeberg, Bad Segeberg, Germany Full list of author information is available at the end of the article

\section{Results}

The median age of the evaluated patients was 81 years (range 61-90y) and 60\% were women. At baseline MRI, the median LV ejection fraction was $58.0 \%$ (range 22.1-71.7\%), which improved significantly at follow-up to $63.4 \%$ (range $24.0-73.7 \%, \mathrm{p}<0.0001$ ).

In addition, a significant reduction of $\mathrm{LV}$ end-diastolic volume $(139.7 \mathrm{ml}$, range $69.4-260.7 \mathrm{ml}$, vs. $129.7 \mathrm{ml}$, range $78.7-272.2 \mathrm{ml}, \mathrm{p}=0.0017)$ and of $\mathrm{LV}$ mass $(151.4 \pm$ $34.1 \mathrm{~g}$ vs. 139. $\pm 33.5 \mathrm{~g}, \mathrm{p}<0.0001)$ was observed.

Baseline MRI identified no AR in 15 patients, grade I AR in 55, grade II in 9 and grade III AR in 2 patients. The median aortic RF was $4.2 \%$ (range 0.1 to $39.0 \%$ ) at baseline and remained stable with $5.0 \%$ (range 0.0 to $41.9 \%, \mathrm{p}=0.02$ ) at follow-up.

The changes in LV function, volume and mass observed in the oberall cohort were not present in the subgroup of patients with relevant AR (grade II and III, $\mathrm{n}=11)$ at baseline MRI: the mean ejection fraction only showed a trend to improvement $(48.8 \pm 15.7 \%$ vs. $50.9 \pm 15.0 \%, \mathrm{p}=0.08)$ whereas the mean LV end-diastolic volume $(183.3 \pm 50.1 \mathrm{ml}$ vs. $184.6 \pm 55.9 \mathrm{ml}, \mathrm{p}=0.90)$ and LV mass $(174.9 \pm 25.8 \mathrm{~g}$ vs. $172.8 \pm 41.3 \mathrm{~g}, \mathrm{p}=0.84)$ were almost identical at baseline and follow-up.

\section{Conclusions}

Using cardiac MRI in TAVI patients, a significant improvement of left ventricular function, volume and mass can be documented after TAVI. Aortic regurgitation which is mostly mild is commonly seen in patients treated with TAVI. The aortic regurgitant fraction remained stable over time. Yet, positive left ventricular 
remodelling could only be observed in patients with no or mild AR after TAVI whereas no changes occured in the subgroup of patients with relevant AR.

\section{Funding}

None.

\section{Authors' details}

${ }^{1}$ Cardiology, Herzzentrum Bad Segeberg, Bad Segeberg, Germany.

${ }^{2}$ Radiology, Segeberger Kliniken, Bad Segeberg, Germany.

Published: 3 February 2015

doi:10.1186/1532-429X-17-S1-085

Cite this article as: Merten et al: Left ventricular remodelling and prosthetic valve function after transcatheter aortic valve implantation:

A serial cardiac magnetic resonance imaging study. Journal of

Cardiovascular Magnetic Resonance 2015 17(Suppl 1):085.

Submit your next manuscript to BioMed Central and take full advantage of:

- Convenient online submission

- Thorough peer review

- No space constraints or color figure charges

- Immediate publication on acceptance

- Inclusion in PubMed, CAS, Scopus and Google Scholar

- Research which is freely available for redistribution

Submit your manuscript at www.biomedcentral.com/submit 